\title{
Implicações da origem das linhagens de feijoeiro na magnitude da interação com ambientes
}

\author{
Camila Andrade Silva( ${ }^{(1)}$, Ângela de Fátima Barbosa $\mathrm{Abreu}^{(2)}$, Magno Antonio Patto Ramalho(1) \\ e José Eustáquio de Souza Carneiro(3)
}

\begin{abstract}
(1)Universidade Federal de Lavras, Departamento de Biologia, Caixa Postal 3.037, CEP 37200-000 Lavras, MG. E-mail: camilaagro01@yahoo.com.br, magnoapr@Ufla.br (2)Embrapa Arroz e Feijão, Rodovia GO-462, Km 12, Zona Rural, Caixa Postal 179, CEP 75375-000 Santo Antônio de Goiás, GO. E-mail: afbabreu@Ufla.br ${ }^{(3)}$ Universidade Federal de Viçosa, Departamento de Fitotecnia, Avenida P. H. Rolfs, s/no, CEP 36.570-000 Viçosa, MG. E-mail: jesc@ufv.br
\end{abstract}

Resumo - O objetivo deste trabalho foi verificar as implicações da origem de linhagens de feijão na magnitude da interação com ambientes e os fatores ambientais que mais contribuem para esta interação. Foram utilizados dados dos experimentos de valor de cultivo e uso, conduzidos em Lavras e Viçosa, MG, nos biênios 2002/2003, 2005/2006 e 2007/2008, nas safras de cultivo das águas, seca e inverno. Foram avaliadas linhagens da Universidade Federal de Lavras, da Universidade Federal de Viçosa e da Embrapa. Os dados de produtividade de grãos foram submetidos a análises de variância por ambiente e análises conjuntas por biênio, para cada local e para os dois locais em conjunto. Foram estimados os coeficientes de determinação de cada fonte de variação, e foram realizadas análises de estabilidade por meio das estimativas de ecovalência. As interações que envolveram as linhagens tiveram pequena participação na variação total nos três biênios. Apesar de ter havido significância das interações genótipo x local quanto à variação total, sua magnitude não foi expressiva. O local de origem não influencia a estabilidade das linhagens quando as suas condições ambientais são semelhantes às do local de cultivo, mas interfere no desempenho das linhagens quando as condições ambientais são muito diferentes.

Termos para indexação: Phaseolus vulgaris, ecovalência, estabilidade, interação genótipo x ambiente.

\section{Implications of the origem of bean lines in the magnitude of the interaction with environments}

\begin{abstract}
The objective of this work was to verify the implications of the origens of bean lines in the magnitude of the interaction with environment, and the environmental factors, which contribute most to this interaction. Data from the value of cultivation and use trials of the biennia 2002/2003, 2005/2006, and 2007/2008, related to three cropping seasons in Lavras and Viçosa counties, MG, Brazil, were used. Lines from Universidade Federal de Lavras, Universidade Federal de Viçosa, and Embrapa were evaluated. Grain yield data were subjected to the variance analysis for each environment and to joint analyses per biennium, for each local, and for both localities simultaneously. Coefficients of determination for each source of variation were determined, and stability analyses using ecovalence estimates were performed. Interactions with lines had small share in the total variation, in the three biennia. Despite the significance of genotype $\mathrm{x}$ local interactions for the total variation, its magnitud was not expressive. The location of the origin does not influence line stability when its environmental conditions are similar to those of the cultivation location, but influence the performance of lines when enviromental conditions differ greatly.
\end{abstract}

Index terms: Phaseolus vulgaris, ecovalence, stability, genotype x environment interaction.

\section{Introdução}

Minas Gerais, segundo maior produtor de feijão do Brasil, é responsável por $18,7 \%$ da produção nacional (Companhia Nacional de Abastecimento, 2011). O feijoeiro é cultivado em praticamente todos os municípios do Estado, muitas vezes em três safras: a das águas, com semeadura nos meses de outubro a novembro; a da seca, com semeadura de fevereiro a março; e a de inverno, com semeadura de julho a agosto. Estima-se que o feijão seja cultivado em $295 \mathrm{mil}$ propriedades desse Estado (Borém \& Carneiro, 2006).

A variação do tipo de solo entre os locais de cultivo, da tecnologia empregada pelos agricultores, do clima e das épocas de semeadura, entre outros fatores, resulta em variações ambientais de grande magnitude. Para atender a essa diversidade de sistemas de cultivo, os programas de melhoramento genético do feijoeiro têm

Pesq. agropec. bras., Brasília, v.46, n.7, p.720-728, jul. 2011 
como principal objetivo a obtenção de linhagens mais produtivas, com boa estabilidade de produção, e que apresentem outras características de interesse, tais como: resistência a doenças, qualidade nutricional, tolerância a estresses abióticos etc (Ramalho \& Abreu, 2006).

A ocorrência de interação genótipo $\mathrm{x}$ ambiente faz com que o comportamento das linhagens não seja consistente ao longo dos ambientes de cultivo, o que é um empecilho ao trabalho dos melhoristas. Vários experimentos têm sido realizados com a cultura do feijoeiro para avaliar a interação genótipo $\mathrm{x}$ ambiente no Estado de Minas Gerais (Oliveira et al., 2006; Matos et al., 2007; Gonçalves et al., 2009) e em outros estados, como Paraná e São Paulo (Melo et al., 2007), Goiás (Pereira et al., 2009), Bahia (Carvalho et al., 2006) e Santa Catarina (Rocha et al., 2009).

Matos et al. (2007) procuraram elucidar qual fator ambiental (local, ano ou safra) mais contribuiu para a interação em Minas Gerais e verificaram que as interações genótipo $\mathrm{x}$ local foram quase sempre superiores às que envolveram safras e anos. Além disso, as interações genótipo x safra foram de maior magnitude do que a de genótipo $\mathrm{x}$ ano. Portanto, os autores recomendam que os programas de melhoramento procurem avaliar as linhagens no maior número de locais possível. Ramalho et al. (1993), em avaliação de linhagens de feijão nas três safras de cultivo em Minas Gerais, e Ramalho et al. (1998), em avaliação das safras da seca e inverno, verificaram que a interação genótipo $\mathrm{x}$ safra é mais expressiva do que a de genótipo x local e recomendaram que as avaliações de linhagens de feijão sejam feitas durante várias safras, em detrimento de locais. Nos estados de Santa Catarina e Paraná, Pereira et al. (2010) verificaram que a interação genótipo $\mathrm{x}$ épocas apresentou menor importância do que as interações genótipo x local e genótipo $\mathrm{x}$ ano. Os autores atribuíram esse resultado à menor variação climática entre épocas nesses estados.

No Estado de Minas Gerais, os programas de melhoramento do feijoeiro são conduzidos pelas Universidades Federais de Lavras (Ufla) e de Viçosa (UFV), em conjunto com a Empresa de Pesquisa Agropecuária de Minas Gerais (Epamig). Além dessas instituições, localizadas no Estado, a Embrapa, em seu programa de melhoramento, gera inúmeras linhagens que são avaliadas não só em Minas Gerais, mas em praticamente todos os estados do Brasil. As progênies geradas em cada programa, nas gerações iniciais, normalmente são avaliadas em poucos locais, em razão da pequena disponibilidade de sementes e do alto custo dos experimentos. Nas gerações mais avançadas, após a identificação das linhagens mais promissoras, elas são avaliadas nos ensaios de valor de cultivo e uso (VCU), em um grande número de ambientes, que devem representar as diversas condições ambientais (locais e safras) às quais as linhagens podem ser submetidas (Brasil, 2006).

Como as linhagens são geradas em diferentes regiões do Estado e mesmo em outros estados, a interação genótipo $\mathrm{x}$ local, possivelmente, tem influência sobre a estabilidade delas. É provável que linhagens obtidas em determinado local se mostrem mais estáveis quando avaliadas nesse mesmo ambiente e menos estáveis quando avaliadas em outro. Contudo, não foram encontrados na literatura trabalhos que procurassem estudar essas hipóteses.

$\mathrm{O}$ objetivo deste trabalho foi verificar as implicações do local de origem das linhagens na magnitude da interação com ambientes e os fatores ambientais que mais contribuem para a interação.

\section{Material e Métodos}

Foram utilizados três conjuntos de dados de produtividade de grãos $\left(\mathrm{kg} \mathrm{ha}^{-1}\right)$, provenientes de ensaios de VCU conduzidos em duas localidades do Estado de Minas Gerais: Lavras, na região sul do Estado, a $21^{\circ} 14^{\prime} \mathrm{S}$ e $45^{\circ} 00^{\prime} \mathrm{W}$, à altitude de $919 \mathrm{~m}$; e Viçosa, na Zona da Mata, a $20^{\circ} 45^{\prime} \mathrm{S}$ e $42^{\circ} 51^{\prime} \mathrm{W}$, à altitude de $648 \mathrm{~m}$. Nesses experimentos, foram avaliadas linhagens dos programas de melhoramento da Ufla, da UFV e da Embrapa Arroz e Feijão (Tabela 1). Os dados foram oriundos de 11 experimentos, conduzidos durante o biênio 2002/2003, 11 no biênio 2005/2006 e 11 no $2007 / 2008$, durante as três safras de cultivo, nos dois locais. Esses locais foram escolhidos em razão de serem os ambientes onde foram desenvolvidas as linhagens da Ufla (Lavras) e da UFV (Viçosa). As linhagens da Embrapa Arroz e Feijão foram desenvolvidas em Santo Antônio de Goiás (GO) e Ponta Grossa (PR), fora, portanto, do ambiente de condução dos VCUs de Minas Gerais. 
Adotou-se o delineamento experimental de blocos ao acaso, com três repetições e parcelas compostas por quatro linhas de $4 \mathrm{~m}$ de comprimento, espaçadas de 0,5 m. As duas linhas centrais de cada parcela foram colhidas para obtenção da produtividade de grãos.

Os dados obtidos foram submetidos a análises de variância por ambiente, tendo-se estimado a acurácia seletiva (AS) por meio da expressão AS $=\left[(1-(1 / \mathrm{F})]^{0,5}\right.$, em que $\mathrm{F}$ é o valor do teste $\mathrm{F}$ para a fonte de variação linhagens (Resende \& Duarte, 2007).

Posteriormente, após a verificação da homogeneidade das variâncias dos resíduos, realizaram-se análises conjuntas por biênio, tendo-se utilizado o SAS 9.2 (SAS Institute, 2008). Para a realização dessas análises, como os dados foram desbalanceados por falta de uma safra em cada biênio, foi utilizado o recurso Proc GLM do SAS, que permite a análise de dados desbalanceados, sem comprometer os resultados (Mondardo, 1994). Nas análises conjuntas, foram estimados os coeficientes de determinação de cada fonte de variação $\left(\mathrm{R}^{2}\right)$, por meio da expressão $\mathrm{R}_{\mathrm{i}}{ }_{\mathrm{i}}=\mathrm{SQ}_{\mathrm{i}} / \mathrm{SQ}_{\mathrm{t}}$, em que: $\mathrm{SQ}_{\mathrm{i}}$ é a soma de quadrados da fonte de variação i e $\mathrm{SQ}_{\mathrm{t}}$ é a soma de quadrados total. As médias das linhagens, em cada biênio, foram agrupadas por meio do teste de Scott-Knott (1974), a $5 \%$ de probabilidade.

Para estimar a contribuição de cada linhagem para a interação, foi realizada a análise de estabilidade conforme Wricke (1965), tendo-se considerado todos os experimentos conduzidos em cada biênio, em cada local. Para isso, foi utilizado o programa Genes (Cruz, 2006).

\section{Resultados e Discussão}

As análises de variância individuais e a produtividade média de grãos obtida nos experimentos evidenciam ampla variação nas condições ambientais em que as linhagens foram avaliadas (Tabela 2). As estimativas de acurácia foram de alta magnitude $(\geq 70<90)$ ou muito alta ( $\geq 90)$ em $74 \%$ (24 de 33) dos casos, o que indica boa precisão experimental. O uso da acurácia como medida de precisão experimental, sugerido por Resende \& Duarte (2007), tem a vantagem de independer da

Tabela 1. Instituições de origem das linhagens de feijoeiro, avaliadas nos ensaios de valor de cultivo e uso conduzidos no Estado de Minas Gerais, nos biênios 2002/2003, 2005/2006 e 2007/2008.

\begin{tabular}{|c|c|c|c|c|c|}
\hline \multicolumn{2}{|c|}{ Biênio 2002/2003 } & \multicolumn{2}{|c|}{ Biênio 2005/2006 } & \multicolumn{2}{|c|}{ Biênio 2007/2008 } \\
\hline Linhagem & Origem & Linhagem & Origem & Linhagem & Origem \\
\hline CNFC 9437 & Embrapa & BRS Horizonte & Embrapa & CNFC 10720 & Embrapa \\
\hline CNFE 8017 & Embrapa & CNFC 8059 & Embrapa & CNFC 10722 & Embrapa \\
\hline OP-S-30 & Ufla & CNFC 10476 & Embrapa & CNFC 10764 & Embrapa \\
\hline OP-S-82 & Ufla & CNFC 10453 & Embrapa & CNFC 9500 & Embrapa \\
\hline BRSMG Majestoso & Ufla & CNFC 8075 & Embrapa & CNFC 9504 & Embrapa \\
\hline OP-S-16 & Ufla & CNFC 10443 & Embrapa & CNFC 9506 & Embrapa \\
\hline OP-S-193 & Ufla & CNFC 8065 & Embrapa & BRS Cometa & Embrapa \\
\hline AN-LAV-51 & Ufla & RC-I-8 & Ufla & BRS Estilo & Embrapa \\
\hline CIII-R-3-19 & Ufla & Z-22 & Ufla & MAII-2 & Ufla \\
\hline CIII-H-4-12 & Ufla & MAI-2.5 & Ufla & MAII-16 & Ufla \\
\hline VC-1 & UFV & CV-46 & Ufla & MAII-22 & Ufla \\
\hline $\mathrm{VC}-2$ & UFV & MAI-18.13 & Ufla & CVIII-39-24 & Ufla \\
\hline $\mathrm{VC}-3$ & UFV & MAI-8.9 & Ufla & CVIII-85-11 & Ufla \\
\hline $\mathrm{VC}-4$ & UFV & CV-55 & Ufla & CVIII-119-4 & Ufla \\
\hline VC-5 & UFV & BRSMG Majestoso & Ufla & BP-31 & Ufla \\
\hline VI 0669C & UFV & VC-3 & UFV & RP-1 & Ufla \\
\hline BRSMG Pioneiro & UFV & VC-6 & UFV & RP- 2 & Ufla \\
\hline VI 4599C & UFV & $\mathrm{VC}-7$ & UFV & BRSMG Majestoso & Ufla \\
\hline- & - & VC-8 & UFV & BRSMG Pioneiro & UFV \\
\hline- & - & VC-9 & UFV & VC-3 & UFV \\
\hline- & - & VC-10 & UFV & VC-13 & UFV \\
\hline- & - & VC-11 & UFV & VC-14 & UFV \\
\hline- & - & VC-12 & UFV & VC-15 & UFV \\
\hline- & - & - & - & VC-16 & UFV \\
\hline
\end{tabular}


magnitude da média e de melhor refletir o que se deseja do experimento de avaliação de linhagens, ou seja, a segurança em se utilizar a expressão fenotípica como indicador da variação genotípica.

Os resultados das análises conjuntas de variância, em todos os biênios, mostraram significância de praticamente todas as fontes de variação $(p \leq 0,01)$ (Tabela 3). A significância da fonte de variação linhagens mostra que elas diferem quanto ao seu potencial produtivo, condição essencial para o estudo da interação genótipo x ambiente.

As estimativas de contribuição das diferentes fontes de variação, por meio do $\mathrm{R}^{2}$, variaram amplamente. Nos biênios 2002/2003 e 2005/2006, a maior contribuição foi da fonte de variação safras. No biênio 2007/2008, a fonte de variação locais foi responsável pela maior parte da variação total. A contribuição da fonte de variação linhagens, embora significativa $(p \leq 0,01)$ em todos os biênios, foi em média de $6,4 \%$. Essa variação quanto à importância das fontes de variação, em cada conjunto de dados, também foi relatada em outros trabalhos (Ramalho et al., 1998; Pereira et al., 2010) e indica que é necessário que este tipo de estudo (com diferentes genótipos, safras, anos e locais) seja repetido, para se obterem conclusões mais confiáveis em relação à contribuição das diferentes fontes de variação para a interação.

Todas as interações foram significativas $(p \leq 0,01)$, contudo, a contribuição relativa foi muito discrepante. No biênio 2002/2003, as interações local x ano, local x safra e local x safra $\mathrm{x}$ ano foram responsáveis por 17,2, 11,5 e $12,6 \%$ da variação, respectivamente, o que representou $41,3 \%$ de toda variação. Portanto, as seis fontes de variação que envolveram linhagens, nesse biênio, explicaram apenas $13 \%$ da variação total. De modo geral, nos demais biênios, os valores mantiveram a mesma tendência.

A interação genótipo x ambiente, em experimentos conduzidos na mesma região, é frequente na cultura do feijoeiro (Ramalho et al., 1993, 1998; Oliveira et al., 2006; Matos et al., 2007). Em alguns estudos, semelhantemente ao verificado no presente trabalho,

Tabela 2. Análise de variância individual, produtividade de grãos $\left(\mathrm{kg} \mathrm{ha}^{-1}\right)$ de linhagens de feijoeiro e de acurácia seletiva (AS, \%) de ensaios de valor de cultivo e uso em Lavras e Viçosa, MG, nos biênios 2002/2003, 2005/2006 e 2007/2008.

\begin{tabular}{|c|c|c|c|c|c|c|c|c|c|}
\hline \multirow[t]{2}{*}{ Safra } & \multicolumn{4}{|c|}{ Lavras } & \multicolumn{4}{|c|}{ Viçosa } & \multirow[t]{2}{*}{ Médi } \\
\hline & $\mathrm{QM}_{\mathrm{L}}$ & $\mathrm{QM}_{\mathrm{E}}$ & Produtividade & AS & $\mathrm{QM}_{\mathrm{L}}$ & $\mathrm{QM}_{\mathrm{E}}$ & Produtividade & AS & \\
\hline & \multicolumn{9}{|c|}{ Biênio 2002/2003 } \\
\hline Inverno 2002 & $242.213^{*}$ & 191.256 & 3.098 & 46 & $622.408^{*}$ & 85.467 & 2.570 & 93 & 2.834 \\
\hline Águas 2002/2003 & $269.529 *$ & 96.841 & 2.798 & 80 & $176.171^{*}$ & 77.854 & 1.039 & 75 & 1.919 \\
\hline Seca 2003 & $263.879 *$ & 99.667 & 2.213 & 79 & $399.317^{*}$ & 160.994 & 2.324 & 77 & 2.269 \\
\hline Inverno 2003 & $236.586^{*}$ & 196.719 & 2.389 & 41 & $312.117^{*}$ & 94.459 & 3.829 & 84 & 3.109 \\
\hline Águas 2003/2004 & $160.011 *$ & 93.764 & 2.014 & 65 & - & - & - & - & 2.014 \\
\hline Seca 2004 & $300.504 *$ & 97.312 & 2.023 & 82 & $317.681^{*}$ & 39.000 & 2.160 & 94 & 2.092 \\
\hline \multirow[t]{2}{*}{ Média } & & & 2.423 & & & & 2.384 & & \\
\hline & \multicolumn{9}{|c|}{ Biênio 2005/2006 } \\
\hline Seca 2005 & $665.524^{*}$ & 201.870 & 2.359 & 84 & $1.692 .018 *$ & 332.205 & 3.281 & 89 & 2.820 \\
\hline Inverno 2005 & $349.999 *$ & 193.903 & 2.653 & 67 & - & - & - & - & 2.653 \\
\hline Águas 2005/2006 & $375.574 *$ & 236.184 & 2.266 & 61 & $360.259^{*}$ & 63.174 & 2.759 & 91 & 2.513 \\
\hline Seca 2006 & $270.461 *$ & 246.235 & 2.280 & 30 & $320.665^{*}$ & 109.480 & 2.337 & 82 & 2.309 \\
\hline Inverno 2006 & $532.308^{*}$ & 270.439 & 3.221 & 70 & $617.707^{*}$ & 55.364 & 2.343 & 97 & 2.782 \\
\hline Águas 2006/2007 & $561.219^{*}$ & 111.973 & 2.148 & 89 & $1.614 .870^{*}$ & 120.260 & 796 & 96 & 1.472 \\
\hline \multirow[t]{2}{*}{ Média } & & & 2.488 & & & & 2.303 & & \\
\hline & \multicolumn{9}{|c|}{ Biênio 2007/2008 } \\
\hline Inverno 2007 & $627.904 *$ & 74.314 & 1.828 & 94 & $488.852 *$ & 92.441 & 2.839 & 90 & 2.334 \\
\hline Águas 2007/2008 & $682.242 *$ & 254.139 & 2.152 & 79 & $324.141^{*}$ & 101.181 & 2.858 & 83 & 2.505 \\
\hline Seca 2008 & $287.557^{*}$ & 126.394 & 2.392 & 75 & $199.390 *$ & 134.678 & 3.317 & 57 & 2.855 \\
\hline Inverno 2008 & $476.438^{*}$ & 398.560 & 2.916 & 41 & $358.638 *$ & 205.767 & 2.765 & 89 & 2.841 \\
\hline Águas 2008/2009 & $364.033^{*}$ & 107.055 & 1.488 & 84 & - & - & - & - & 1.488 \\
\hline Seca 2009 & $250.709 *$ & 165.704 & 1.676 & 58 & $386.559 *$ & 109.335 & 2.277 & 84 & 1.977 \\
\hline Média & & & 2.075 & & & & 2.811 & & \\
\hline
\end{tabular}

*Significativo pelo teste $\mathrm{F}$, a $1 \%$ de probabilidade. $\mathrm{QM}_{\mathrm{L}}$, quadrado médio da fonte de variação linhagem; $\mathrm{QM}_{\mathrm{E}}$, quadrado médio do resíduo. 
foi estimada a contribuição relativa das fontes de variação e, nesses casos, constatou-se que, embora as interações que envolveram genótipos tenham sido sempre significativas, a participação para a variação total dificilmente atingiu 20\% (Ramalho et al., 1993; Matos et al., 2007). Ramalho et al. (1993, 1998) verificaram que a interação genótipo $\mathrm{x}$ safra (épocas de semeadura) foi mais expressiva do que a de genótipo $\mathrm{x}$ local, em Minas Gerais. Os autores recomendaram que as avaliações de linhagens de feijão sejam conduzidas durante as várias safras, em detrimento da variabilidade de locais. Pereira et al. (2010) constataram que a avaliação de genótipos em vários locais ou anos, no Paraná e em Santa Catarina, é mais importante que a avaliação nas diferentes safras.

Ao observar as estimativas de ecovalência por local de avaliação das linhagens (Tabela 4), verificase que no biênio 2002/2003, a linhagem OP-S-193 foi responsável pela maior contribuição para a interação em Lavras $(15,80 \%)$. Na avaliação em Viçosa, essa linhagem contribuiu com apenas $6,32 \%$ e, como ela foi desenvolvida em Lavras, em princípio, esse resultado não era esperado. Assim, linhagens desenvolvidas em um local podem apresentar elevada contribuição para interação nesse mesmo local, o que indica que a origem da linhagem não interferiu na estabilidade das linhagens.

$\mathrm{Na}$ avaliação do biênio 2007/2008, em Lavras, a linhagem CNFC 9506 contribuiu com 16,60\% para a interação (Tabela 4). Na média dos dois locais, essa linhagem foi a que mais contribuiu nesse biênio (Tabela 5) e, ao se individualizarem os locais, observa-se que a avaliação em Lavras foi responsável por essa linhagem ter tido um baixo desempenho médio $\left(2,24 \mathrm{Mg} \mathrm{ha}^{-1}\right)$ em relação às outras linhagens $\left(2,41 \mathrm{Mg} \mathrm{ha}^{-1}\right)$. O mesmo comentário é válido para a linhagem CNFC 8059, na avaliação feita no biênio 2005/2006, em que a contribuição dessa linhagem para a interação, quando avaliada em Viçosa, foi de 11,70\% (Tabela 4). Na safra das águas 2005/2006, essa linhagem teve média de produtividade de apenas $800 \mathrm{~kg} \mathrm{ha}^{-1} \mathrm{e}$, provavelmente, essa baixa produtividade acarretou a elevada contribuição para a interação dessa linhagem.

No geral, pode-se observar a ocorrência de linhagens desenvolvidas em Viçosa com elevada contribuição para a interação, quando avaliadas nesse mesmo local, e baixa contribuição na avaliação em Lavras e, da mesma forma, linhagens desenvolvidas em Lavras com elevada contribuição para a interação

Tabela 3. Resumo das análises de variância conjuntas quanto à produtividade de grãos $\left(\mathrm{kg} \mathrm{ha}^{-1}\right)$ de linhagens de feijoeiro nos ensaios de valor de cultivo e uso, em Lavras e Viçosa, MG, nos biênios 2002/2003, 2005/2006 e 2007/2008, e os respectivos coeficientes de determinação $\left(\mathrm{R}^{2}\right)$ de cada fonte de variação.

\begin{tabular}{|c|c|c|c|c|c|c|c|c|c|}
\hline \multirow[t]{2}{*}{ Fonte de variação } & \multicolumn{3}{|c|}{ Biênio 2002/2003 } & \multicolumn{3}{|c|}{ Biênio 2005/2006 } & \multicolumn{3}{|c|}{ Biênio 2007/2008 } \\
\hline & GL & QM & $\mathrm{R}^{2}(\%)$ & GL & $\mathrm{QM}$ & $\mathrm{R}^{2}(\%)$ & GL & QM & $\mathrm{R}^{2}(\%)$ \\
\hline Ano (A) & 1 & $2.986 .315^{*}$ & 0,7 & 1 & $42.691 .505^{* *}$ & 8,2 & 1 & $22.655 .686^{* *}$ & 4,9 \\
\hline Local (L) & 1 & 83.849 & 0,1 & 1 & $3.571 .451^{* *}$ & 0,7 & 1 & $97.837 .482 * *$ & 21,1 \\
\hline Safra (S) & 2 & $56.610 .531 * *$ & 28,0 & 2 & $43.571 .208^{* *}$ & 16,7 & 2 & $7.784 .956 * *$ & 3,4 \\
\hline Linhagem (C) & 17 & $909.866^{* *}$ & 3,8 & 22 & $2.010 .774 * *$ & 8,5 & 23 & $1.390 .749 * *$ & 6,9 \\
\hline$A \times L$ & 1 & $69.628 .976^{* *}$ & 17,2 & 1 & $107.251 .015^{* *}$ & 20,6 & 1 & $11.385 .590^{* *}$ & 2,5 \\
\hline $\mathrm{A} \times \mathrm{S}$ & 2 & $5.091 .373 * *$ & 2,5 & 2 & $9.488 .182 * *$ & 3,6 & 2 & $42.785 .115^{* *}$ & 18,5 \\
\hline $\mathrm{A} \times \mathrm{C}$ & 17 & $197.126^{* *}$ & 0,8 & 22 & $476.722 * *$ & 2,0 & 23 & $522.208 * *$ & 2,6 \\
\hline $\mathrm{L} \times \mathrm{S}$ & 2 & $23.144 .801 * *$ & 11,5 & 2 & $15.159 .686^{* *}$ & 5,8 & 2 & $2.817 .864 * *$ & 1,2 \\
\hline $\mathrm{L} \times \mathrm{C}$ & 17 & $148.988 * *$ & 0,6 & 22 & $532.057 * *$ & 2,2 & 23 & $255.018 * *$ & 1,3 \\
\hline $\mathrm{S} \times \mathrm{C}$ & 34 & $269.216^{* *}$ & 2,3 & 44 & $416.807^{* *}$ & 3,5 & 46 & $340.814^{* *}$ & 3,4 \\
\hline$A \times L \times C$ & 17 & $198.061 * *$ & 0,8 & 22 & $251.289 * *$ & 1,1 & 23 & $339.137 * *$ & 1,7 \\
\hline $\mathrm{A} \times \mathrm{S} \times \mathrm{C}$ & 34 & $202.725 * *$ & 1,7 & 44 & $390.618 * *$ & 3,3 & 46 & $268.080 * *$ & 2,7 \\
\hline $\mathrm{L} \times \mathrm{S} \times \mathrm{C}$ & 34 & $247.900 * *$ & 2,1 & 44 & $443.447 * *$ & 3,7 & 46 & $515.878 * *$ & 5,1 \\
\hline$A \times L \times S$ & 2 & $25.519 .929 * *$ & 12,6 & 2 & $8.278 .305^{* *}$ & 3,2 & 2 & $3.157 .882 * *$ & 2,7 \\
\hline $\mathrm{A} \times \mathrm{L} \times \mathrm{S} \times \mathrm{C}$ & 16 & $406.691 * *$ & 4,7 & 21 & $135.071 * *$ & 1,6 & 22 & $322.537^{* *}$ & 4,6 \\
\hline Erro-médio & 374 & 112.066 & 10,4 & 484 & 164.905 & 15,3 & 506 & $159.960,82$ & 17,5 \\
\hline AS (\%) & \multicolumn{3}{|c|}{93,6} & \multicolumn{3}{|c|}{95,8} & \multicolumn{3}{|c|}{94,1} \\
\hline Média $\left(\mathrm{kg} \mathrm{ha}^{-1}\right)$ & \multicolumn{3}{|c|}{2.405} & \multicolumn{3}{|c|}{2.404} & \multicolumn{3}{|c|}{2.410} \\
\hline
\end{tabular}

* e **Significativo pelo teste $\mathrm{F}$, a 5 e $1 \%$ de probabilidade, respectivamente. 
em Lavras e baixa em Viçosa, o que evidencia que, dentro da mesma região, a origem da linhagem não interfere no seu desempenho. Nesse caso, apesar da significância das interações genótipo x local para a variação total, não se observou relação direta entre a origem das linhagens e a estabilidade nos locais de avaliação.

No biênio 2002/2003, na avaliação em Lavras, as linhagens desenvolvidas em Viçosa apresentaram maior média de produtividade de grãos e, na avaliação em Viçosa, as linhagens originadas em Lavras e em Viçosa tiveram médias semelhantes (Tabela 6). No biênio 2005/2006, as linhagens desenvolvidas em Viçosa tiveram maiores médias nas avaliações em Lavras e Viçosa. No biênio 2007/2008, tanto na avaliação em Lavras quanto em Viçosa, as linhagens com origem em Lavras tiveram as maiores médias de produtividade de grãos.
Dessa forma, pelos dados de médias entre as linhagens de Lavras e Viçosa, a origem não teve influência no desempenho das linhagens. Contudo, isso somente foi verdadeiro para regiões com características ambientais semelhantes. Quando as linhagens de Lavras e Viçosa foram comparadas às da Embrapa, nos ensaios de VCU de Minas Gerais, em todos os biênios, as linhagens da Embrapa foram, em média, menos produtivas. Isso indica que o local de origem das linhagens pode interferir em seu desempenho, desde que as condições ambientais do local de cultivo sejam bem distintas das do local de origem. Entretanto, mesmo com a ocorrência da interferência do local de origem sobre a produtividade, no caso das linhagens da Embrapa cultivadas em Minas, foi possível identificar linhagens da Embrapa entre as mais produtivas em todos os biênios. Esse fato é de extrema importância, já que esclarece que uma linhagem desenvolvida em

Tabela 4. Estimativas de ecovalência $\left(\mathrm{W}_{\mathrm{i}}^{2} \%\right.$ ) de linhagens de feijoeiro, em Lavras e Viçosa, MG, nos biênios 2002/2003, $2005 / 2006$ e 2007/2008.

\begin{tabular}{|c|c|c|c|c|c|c|c|c|}
\hline \multicolumn{3}{|c|}{ Biênio 2002/2003 } & \multicolumn{3}{|c|}{ Biênio 2005/2006 } & \multicolumn{3}{|c|}{ Biênio 2007/2008 } \\
\hline Linhagem & Lavras & Viçosa & Linhagem & Lavras & Viçosa & Linhagem & Lavras & Viçosa \\
\hline $\mathrm{VC} 1$ & 7,67 & 6,08 & RC-I-8 & 8,48 & 2,98 & CNFC 10720 & 1,96 & 1,10 \\
\hline $\mathrm{VC} 2$ & 7,18 & 10,70 & $\mathrm{Z}-22$ & 2,72 & 0,35 & CNFC 10722 & 3,16 & 3,50 \\
\hline $\mathrm{VC} 3$ & 3,96 & 9,37 & MAI-2,5 & 2,93 & 4,91 & CNFC 10764 & 6,24 & 0,87 \\
\hline $\mathrm{VC} 4$ & 5,12 & 5,75 & CV-46 & 3,84 & 2,30 & CNFC 9500 & 2,35 & 7,50 \\
\hline VC5 & 5,71 & 3,46 & MAI- 18,13 & 4,13 & 3,60 & CNFC 9504 & 6,69 & 5,60 \\
\hline VI 0669C & 2,20 & 6,86 & MAI-8,9 & 2,59 & 3,97 & CNFC 9506 & 16,60 & 2,30 \\
\hline BRSMG Pioneiro & 4,76 & 3,23 & CV-55 & 3,01 & 5,81 & MAII-2 & 1,65 & 5,70 \\
\hline VI 4599C & 7,63 & 2,13 & CNFC 10443 & 3,87 & 1,89 & MAII-16 & 5,33 & 8,00 \\
\hline OP-S-30 & 5,62 & 5,30 & CNFC 8065 & 4,43 & 5,09 & MAII-22 & 3,19 & 13,00 \\
\hline OP-S-82 & 3,29 & 5,74 & CNFC 8059 & 3,36 & 11,7 & CVIII-39-24 & 2,35 & 0,99 \\
\hline BRSMG Majestoso & 3,13 & 2,03 & CNFC 10476 & 1,82 & 6,63 & CVIII-85-11 & 5,51 & 6,10 \\
\hline OP-S-16 & 4,77 & 7,21 & CNFC 10453 & 6,54 & 6,99 & CVIII-119-4 & 1,56 & 1,00 \\
\hline OP-S-193 & 15,80 & 6,32 & CNFC 8075 & 9,48 & 2,28 & BP-31 & 3,62 & 8,20 \\
\hline AN-LAV-51 & 4,44 & 4,79 & VC-6 & 6,93 & 2,40 & RP-1 & 5,86 & 4,70 \\
\hline CIII-R-3-19 & 8,68 & 8,55 & VC-7 & 1,36 & 4,44 & $\mathrm{RP}-2$ & 0,62 & 4,00 \\
\hline CIII-H-4-12 & 0,79 & 3,32 & VC-8 & 3,37 & 0,88 & VC-13 & 5,20 & 3,20 \\
\hline CNFC 9437 & 1,47 & 0,81 & VC-9 & 9,58 & 8,17 & VC-14 & 2,84 & 4,00 \\
\hline CNFE 8017 & 7,65 & 8,21 & VC-10 & 2,38 & 3,44 & VC-15 & 4,69 & 0,26 \\
\hline- & - & - & VC-11 & 3,13 & 3,38 & VC-16 & 3,00 & 0,67 \\
\hline- & - & - & $\mathrm{VC}-12$ & 2,67 & 3,91 & BRSMG Majestoso & 2,51 & 0,22 \\
\hline - & - & - & BRS Horizonte & 3,31 & 4,45 & VC-3 & 3,64 & 7,50 \\
\hline - & - & - & BRSMG Majestoso & 4,80 & 6,17 & BRS Cometa & 5,55 & 4,60 \\
\hline- & - & - & VC-3 & 5,18 & 4,11 & BRS Estilo & 4,60 & 4,30 \\
\hline- & - & - & - & - & - & BRSMG Pioneiro & 1,10 & 1,10 \\
\hline Média Ufla & 5,53 & 5,95 & & 4,06 & 3,76 & & 3,22 & 5,19 \\
\hline Média UFV & 5,82 & 5,41 & & 4,33 & 3,84 & & 3,41 & 2,79 \\
\hline Média Embrapa & 4,56 & 4,51 & & 4,69 & 5,58 & & 5,89 & 3,72 \\
\hline
\end{tabular}


diferentes ambientes pode apresentar desempenho igual ou superior às desenvolvidas especificamente para um determinado local, apesar de, aparentemente, essa chance ser menor.

Para a obtenção de uma nova linhagem, são feitas avaliações por várias gerações. Nessa condição, espera-se que a seleção natural atue e que possam ser identificadas as mais adaptadas àquele ambiente particular (Gonçalves et al., 2001; Pirola et al., 2002; Silva et al., 2004). Assim, esperava-se que as linhagens oriundas de um local tivessem maior adaptabilidade e estabilidade no referido local. Entretanto, há um argumento que pode favorecer o desempenho das linhagens em ambientes diferentes daqueles em que elas foram obtidas, que está relacionado à ocorrência de patógenos. Normalmente, uma linhagem obtida em um dado ambiente foi submetida aos mesmos patógenos por várias gerações, o que possibilita que estes se especializem naquele grupo de linhagens (coevolução patógeno-hospedeiro) e reduzam o desempenho delas significativamente (Guzmán et al., 1995; Carbonell et al., 1999; Pastor-Corrales, 2004). Assim, quando a linhagem é cultivada em outro ambiente, com patógenos diferentes, o seu desempenho pode ser melhor. É comum constatar, em experimentos de avaliação de genótipos, que as linhagens introduzidas apresentam ótimo desempenho nos primeiros anos e, com o decorrer do tempo, elas diminuem esse desempenho. Contudo, o inverso também pode ocorrer, ou seja, as linhagens apresentarem maior resistência aos patógenos predominantes no local onde ocorreu a seleção e menor resistência em locais onde não foram testadas.

Tabela 5. Produtividade de grãos $\left(\mathrm{kg} \mathrm{ha}^{-1}\right)$ e estimativas de ecovalência $\left(\mathrm{W}_{\mathrm{i}}^{2} \%\right)$ de linhagens de feijoeiro, com base na análise conjunta dos ensaios em Lavras e Viçosa, MG nos biênios 2002/2003, 2005/2006 e 2007/2008 ${ }^{(1)}$.

\begin{tabular}{|c|c|c|c|c|c|c|c|c|}
\hline \multicolumn{3}{|c|}{ Biênio 2002/2003 } & \multicolumn{3}{|c|}{ Biênio $2005 / 2006$} & \multicolumn{3}{|c|}{ Biênio 2007/2008 } \\
\hline Linhagem & Produtividade & $\mathrm{W}_{\mathrm{i}}^{2}$ & Linhagem & Produtividade & $\mathrm{W}_{\mathrm{i}}^{2}$ & Linhagem & Produtividade & $\mathrm{W}_{\mathrm{i}}^{2}$ \\
\hline BRSMG Majestoso & $2.637 \mathrm{a}$ & 2,44 & VC-9 & $2.853 \mathrm{a}$ & 9,95 & MAII-22 & $2.727 \mathrm{a}$ & 7,49 \\
\hline VC-3 & $2.625 \mathrm{a}$ & 7,06 & $\mathrm{Z}-22$ & $2.706 \mathrm{a}$ & 1,46 & CVIII-119-4 & $2.716 \mathrm{a}$ & 1,33 \\
\hline $\mathrm{VC}-2$ & $2.617 \mathrm{a}$ & 8,52 & VC-6 & $2.685 \mathrm{a}$ & 4,14 & RP-1 & $2.692 \mathrm{a}$ & 5,28 \\
\hline OP-S-82 & $2.552 \mathrm{a}$ & 4,76 & VC-11 & $2.651 \mathrm{a}$ & 2,94 & MAII-2 & $2.663 \mathrm{a}$ & 3,33 \\
\hline OP-S-193 & $2.527 \mathrm{a}$ & 10,00 & VC-3 & $2.620 \mathrm{a}$ & 4,50 & CNFC 10764 & $2.594 b$ & 4,36 \\
\hline VC-4 & $2.515 \mathrm{a}$ & 5,14 & CV-46 & $2.618 \mathrm{a}$ & 2,79 & MAII-16 & $2.569 \mathrm{~b}$ & 6,09 \\
\hline OP-S-16 & $2.461 \mathrm{~b}$ & 5,88 & VC-10 & $2.587 \mathrm{~b}$ & 3,59 & BRS Estilo & $2.556 \mathrm{~b}$ & 4,20 \\
\hline VI 0669C & $2.424 b$ & 4,73 & CNFC 8075 & $2.548 b$ & 6,22 & CVIII-85-11 & $2.542 b$ & 5,52 \\
\hline OP-S-30 & $2.400 \mathrm{~b}$ & 5,16 & MAI-18.13 & $2.527 \mathrm{~b}$ & 3,72 & VC-3 & $2.500 \mathrm{~b}$ & 6,68 \\
\hline BRSMG Pioneiro & $2.390 \mathrm{~b}$ & 3,74 & $\mathrm{CV}-55$ & $2.501 \mathrm{~b}$ & 3,98 & VC- 15 & $2.471 \mathrm{~b}$ & 2,62 \\
\hline VI 4599C & $2.388 b$ & 5,43 & BRSMG Majestoso & $2.458 \mathrm{~b}$ & 5,06 & BRSMG Majestoso & $2.471 \mathrm{~b}$ & 1,43 \\
\hline CNFE 8017 & $2.387 \mathrm{~b}$ & 7,78 & VC-8 & $2.451 \mathrm{~b}$ & 1,96 & $\mathrm{RP}-2$ & $2.453 b$ & 2,56 \\
\hline CIII-R-3-19 & $2.382 b$ & 8,64 & MAI-2.5 & $2.360 \mathrm{c}$ & 4,03 & CVIII-39-24 & $2.451 \mathrm{~b}$ & 1,86 \\
\hline CIII-H-4-12 & $2.341 b$ & 2,10 & MAI-8.9 & $2.346 \mathrm{c}$ & 3,42 & CNFC 10720 & $2.316 \mathrm{c}$ & 1,62 \\
\hline VC-5 & $2.274 \mathrm{c}$ & 5,76 & CNFC 8059 & $2.301 \mathrm{c}$ & 7,76 & VC-16 & $2.313 \mathrm{c}$ & 1,87 \\
\hline $\mathrm{VC}-1$ & $2.178 \mathrm{c}$ & 6,98 & RC-I-8 & $2.285 \mathrm{c}$ & 5,22 & BP-31 & $2.310 \mathrm{c}$ & 5,25 \\
\hline CNFC 9437 & $2.105 \mathrm{~d}$ & 1,15 & VC-12 & $2.246 \mathrm{c}$ & 2,93 & VC-13 & $2.301 \mathrm{c}$ & 4,11 \\
\hline AN-LAV-51 & $2.081 \mathrm{~d}$ & 4,59 & CNFC 10443 & $2.230 \mathrm{c}$ & 2,63 & VC-14 & $2.300 \mathrm{c}$ & 3,21 \\
\hline- & - & - & CNFC 10476 & $2.217 \mathrm{c}$ & 3,84 & BRSMG Pioneiro & $2.268 \mathrm{c}$ & 1,09 \\
\hline- & - & - & VC-7 & $2.088 \mathrm{~d}$ & 3,03 & CNFC 9506 & $2.241 \mathrm{c}$ & 11,30 \\
\hline- & - & - & CNFC 8065 & $2.081 \mathrm{~d}$ & 5,16 & CNFC 10722 & $2.146 \mathrm{~d}$ & 3,17 \\
\hline- & - & - & CNFC 10453 & $2.049 \mathrm{~d}$ & 7,57 & BRS Cometa & $2.116 \mathrm{~d}$ & 4,96 \\
\hline- & - & - & BRS Horizonte & $1.874 \mathrm{e}$ & 3,99 & CNFC 9500 & $2.111 \mathrm{~d}$ & 4,34 \\
\hline- & - & - & - & - & - & CNFC 9504 & $2.000 \mathrm{~d}$ & 6,17 \\
\hline Média Ufla & 2.423 & 5,45 & & 2.475 & 3,71 & & 2.560 & 4,01 \\
\hline Média UFV & 2.426 & 5,92 & & 2.523 & 4,13 & & 2.359 & 3,26 \\
\hline Média Embrapa & 2.246 & 4,47 & & 2.186 & 5,31 & & 2.260 & 5,02 \\
\hline
\end{tabular}

${ }^{(1)}$ Médias seguidas de letras iguais, nas colunas, pertencem ao mesmo grupo, pelo teste de Scott-Knott, a 5\% de probabilidade. 
Tabela 6. Produtividade de grãos $\left(\mathrm{kg} \mathrm{ha}^{-1}\right)$ de linhagens de feijoeiro, em Lavras e Viçosa, MG nos biênios 2002/2003, $2005 / 2006$ e $2007 / 2008^{(1)}$.

\begin{tabular}{|c|c|c|c|c|c|c|c|c|}
\hline \multicolumn{3}{|c|}{ Biênio 2002/2003 } & \multicolumn{3}{|c|}{ Biênio 2005/2006 } & \multicolumn{3}{|c|}{ Biênio 2007/2008 } \\
\hline Linhagem & Lavras & Viçosa & Linhagem & Lavras & Viçosa & Linhagem & Lavras & Viçosa \\
\hline $\mathrm{VC} 1$ & $2.275 b$ & $2.062 \mathrm{c}$ & RC-I-8 & $2.429 b$ & $2.114 \mathrm{c}$ & CNFC 10720 & $2.033 \mathrm{~b}$ & $2.658 \mathrm{~b}$ \\
\hline $\mathrm{VC} 2$ & $2.636 \mathrm{a}$ & $2.595 \mathrm{a}$ & $\mathrm{Z}-22$ & $2.837 \mathrm{a}$ & $2.550 \mathrm{~b}$ & CNFC 10722 & $1.775 \mathrm{c}$ & $2.592 b$ \\
\hline $\mathrm{VC} 3$ & $2.563 \mathrm{a}$ & $2.701 \mathrm{a}$ & MAI-2,5 & $2.555 b$ & $2.126 \mathrm{c}$ & CNFC 10764 & $2.140 \mathrm{~b}$ & $3.139 \mathrm{a}$ \\
\hline VC4 & $2.552 \mathrm{a}$ & $2.473 \mathrm{a}$ & CV-46 & $2.661 \mathrm{a}$ & $2.568 \mathrm{~b}$ & CNFC 9500 & $1.820 \mathrm{c}$ & $2.460 \mathrm{~b}$ \\
\hline VC5 & $2.165 \mathrm{~b}$ & $2.405 \mathrm{~b}$ & MAI-18,13 & $2.529 \mathrm{~b}$ & $2.525 \mathrm{~b}$ & CNFC 9504 & $1.754 \mathrm{c}$ & $2.296 \mathrm{c}$ \\
\hline VI 0669C & $2.498 \mathrm{a}$ & $2.336 \mathrm{~b}$ & MAI-8,9 & $2.325 b$ & $2.374 \mathrm{c}$ & CNFC 9506 & $2.084 b$ & $2.429 \mathrm{~b}$ \\
\hline BRSMG Pioneiro & $2.381 \mathrm{~b}$ & $2.402 \mathrm{~b}$ & CV-55 & $2.543 b$ & $2.451 \mathrm{~b}$ & MAII-2 & $2.393 \mathrm{a}$ & $2.989 \mathrm{a}$ \\
\hline VI 4599C & $2.512 \mathrm{a}$ & $2.241 \mathrm{~b}$ & CNFC 10443 & $2.357 \mathrm{~b}$ & $2.080 \mathrm{c}$ & MAII-16 & $2.200 \mathrm{~b}$ & $3.013 \mathrm{a}$ \\
\hline OP-S-30 & $2.444 \mathrm{a}$ & $2.347 b$ & CNFC 8065 & $2.022 \mathrm{c}$ & $2.153 \mathrm{c}$ & MAII-22 & $2.479 \mathrm{a}$ & $3.025 \mathrm{a}$ \\
\hline OP-S-82 & $2.502 \mathrm{a}$ & $2.613 \mathrm{a}$ & CNFC 8059 & $2.539 b$ & $2.016 \mathrm{c}$ & CVIII-39-24 & $2.183 b$ & $2.774 \mathrm{a}$ \\
\hline BRSMG Majestoso & $2.626 \mathrm{a}$ & $2.650 \mathrm{a}$ & CNFC 10476 & $2 . .251 \mathrm{c}$ & $2.176 \mathrm{c}$ & CVIII-85-11 & $2.152 b$ & $3.011 \mathrm{a}$ \\
\hline OP-S-16 & $2.523 \mathrm{a}$ & $2.389 b$ & CNFC 10453 & $2.319 b$ & $1.726 \mathrm{~d}$ & CVIII-119-4 & $2.420 \mathrm{a}$ & $3.072 \mathrm{a}$ \\
\hline OP-S-193 & $2.564 \mathrm{a}$ & $2.485 \mathrm{a}$ & CNFC 8075 & $2.782 \mathrm{a}$ & $2.270 \mathrm{c}$ & BP-31 & $1.942 \mathrm{c}$ & $2.753 \mathrm{a}$ \\
\hline AN-LAV-51 & $2.151 b$ & $1.998 \mathrm{c}$ & VC-6 & $2.788 \mathrm{a}$ & $2.563 b$ & RP-1 & $2.283 b$ & $3.184 \mathrm{a}$ \\
\hline CIII-R-3-19 & $2.322 \mathrm{~b}$ & $2.455 \mathrm{a}$ & VC-7 & $2.072 \mathrm{c}$ & $2.109 \mathrm{c}$ & RP-2 & $2 . .002 \mathrm{c}$ & $2.995 \mathrm{a}$ \\
\hline CIII-H-4-12 & $2.388 b$ & $2.286 b$ & VC-8 & $2.578 \mathrm{~b}$ & $2.299 \mathrm{c}$ & VC-13 & $2.000 \mathrm{c}$ & $2.662 b$ \\
\hline CNFC 9437 & $2.158 b$ & $2.044 \mathrm{c}$ & VC-9 & $2.724 \mathrm{a}$ & $3.009 \mathrm{a}$ & VC-14 & $1.925 \mathrm{c}$ & $2.750 \mathrm{a}$ \\
\hline CNFE 8017 & $2.345 b$ & $2.438 \mathrm{a}$ & VC-10 & $2.523 b$ & $2.665 b$ & VC-15 & $2.123 b$ & $2.891 \mathrm{a}$ \\
\hline- & - & - & VC-11 & $2.699 a$ & $2.593 b$ & VC-16 & $1.976 \mathrm{c}$ & $2.718 \mathrm{a}$ \\
\hline - & - & - & VC-12 & $2.351 b$ & $2.120 \mathrm{c}$ & BRSMG Majestoso & $2.145 b$ & $2.863 \mathrm{a}$ \\
\hline- & - & - & BRS Horizonte & $2.069 \mathrm{c}$ & $1.641 \mathrm{~d}$ & VC-3 & $1.971 \mathrm{c}$ & $3.135 \mathrm{a}$ \\
\hline - & - & - & BRSMG Majestoso & $2.474 \mathrm{~b}$ & $2.439 b$ & BRS Cometa & $1.842 \mathrm{c}$ & $2.446 \mathrm{~b}$ \\
\hline- & - & - & $\mathrm{VC}-3$ & $2.797 \mathrm{a}$ & $2.408 b$ & BRS Estilo & $2.244 b$ & $2.930 \mathrm{a}$ \\
\hline- & - & - & - & - & - & BRSMG Pioneiro & $1.918 \mathrm{c}$ & $2.689 \mathrm{~b}$ \\
\hline Média Ufla & 2.440 & 2.403 & & 2.544 & 2.393 & & 2.220 & 2.968 \\
\hline Média UFV & 2.448 & 2.402 & & 2.566 & 2.471 & & 1.985 & 2.807 \\
\hline Média Embrapa & 2.251 & 2.241 & & 2.334 & 2.009 & & 1.962 & 2.619 \\
\hline
\end{tabular}

${ }^{(1)}$ Médias seguidas de letras iguais, nas colunas, pertencem ao mesmo grupo, pelo teste de Scott-Knott, a 5\% de probabilidade.

\section{Conclusões}

1. Apesar da significância das interações genótipo x local, ela é pouco expressiva quanto à sua importância para a variação total.

2. O local de origem não influencia a estabilidade das linhagens quando as suas condições ambientais são semelhantes às do local de cultivo, mas interfere no desempenho das linhagens quando as condições ambientais são muito diferentes.

\section{Referências}

BORÉM, A.; CARNEIRO, S.E.J. A cultura do feijão. In: VIEIRA, C.; PAUlA JÚNIOR, T.J. de; BORÉM, A. (Ed.). Feijão. 2.ed. Viçosa: UFV, 2006. p.13-18.

BRASIL. Ministério da Agricultura, Pecuária e Abastecimento. Requisitos mínimos para determinação do valor de cultivo e uso de feijão (Phaseolus vulgaris), para a inscrição no registro nacional de cultivares - RNC. Brasília: MAPA, 2006. Anexo I.

CARBONELL, S.A.M.; POMPEU, A.S.; FRANCISCO, F.G.; RAVAGNANI, S.; ALMEIDA, A.L.L. Raças fisiológicas de Colletotrichum lindemuthianum e reação de linhagens de feijoeiro no Estado de São Paulo. Fitopatologia Brasileira, v.24, p.60-65, 1999.

CARVALHO, H.W.L. de; FARIA, L.C. de; WARWICK, D.R.N.; ALBUQUERQUE, M.M. de; DEL PELOSO, M.J.; MELO, L.C.; RODRIGUES, A.R. dos S.; RIBEIRO, S.S.; OLIVEIRA, V.D.; SOUZA, E.M. de. Adaptabilidade e estabilidade de genótipos de feijoeiro-comum no Nordeste brasileiro, no ano agrícola de 2005. Agrotrópica, v.18, p.83-88, 2006.

COMPANHIA NACIONAL DE ABASTECIMENTO. Acompanhamento da safra brasileira de grãos 2009/2010: décimo levantamento. Disponível em: <http://www.conab.gov. br/conteudos.php>. Acesso em: 10 maio 2011.

CRUZ, C.D. Programa GENES: estatística experimental e matrizes. Viçosa: UFV, 2006. 285p. 
GONÇALVES, F.M.A.; RAMALHO, M.A.P.; ABREU, Â. de F.B. Natural selection in four common bean traits. Crop Breeding and Applied Biotechnology, v.1, p.213-220, 2001.

GONÇALVES, R.J. de S.; ABREU, Â. de F.B.; RAMALHO, M.A.P.; BRUZI, A.T. Strategies for recommendation of common bean lines tested for value of cultivation and use in different environments. Crop Breeding and Applied Biotechnology, v.9, p.132-139, 2009.

GUZMÁN, P.; GILBERTSON, R.L.; NODARI, R.; JOHNSON, W.C.; TEMPLE, S.R.; MANDALA, D.; MKANDAWIRE, A.B.C.; GEPTS, P. Characterization of variability in the fungus Phaeoisariopsis griseola suggests coevolution with the common bean (Phaseolus vulgaris) Phytopathology, v.85, p.600-607, 1995.

MATOS, J.W. de; RAMALHO, M.A.P.; ABREU, Â. de F.B. Trinta e dois anos do programa de melhoramento genético do feijoeiro em Minas Gerais. Ciência e Agrotecnologia, v.31, p.1749-1754, 2007.

MELO, L.C.; MELO, P.G.S.; FARIA, L.C. de; CABRERA DIAZ, J.L.; DELPELOSO, M.J.; RAVA, C.A.; COSTA, J.G.C. da. Interação com ambientes e estabilidade de genótipos de feijoeiro-comum na Região Centro-Sul do Brasil. Pesquisa Agropecuária Brasileira, v.42, p.715-723, 2007.

MONDARDO, M. Estimabilidade de funções paramétricas com dados desbalanceados do Proc GLM do SAS: aplicações à pesquisa agropecuária. 1994. 166p. Dissertação (Mestrado) Escola Superior de Agricultura Luiz de Queiroz, Piracicaba.

OLIVEIRA, G.V.; CARNEIRO, P.C.S.; CARNEIRO, J.E. de S.; CRUZ, C.D. Adaptabilidade e estabilidade de linhagens de feijão comum em Minas Gerais. Pesquisa Agropecuária Brasileira, V.41, p.257-265, 2006.

PASTOR-CORRALES, M.A. Review of coevolution studies between pathogens and their common bean hosts: implication for the development of disease-resistant beans. Annual Report Bean Improvement Cooperative, v.47, p.67-68, 2004.

PEREIRA, H.S.; MELO, L.C.; FARIA, L.C. de; DEL PELOSO, M.J.; COSTA, J.G.C. da; RAVA, C.A.; WENDLAND, A. Adaptabilidade e estabilidade de genótipos de feijoeiro-comum com grãos tipo carioca na Região Central do Brasil. Pesquisa Agropecuária Brasileira, v.44, p.29-37, 2009.
PEREIRA, H.S.; MELO, L.C.; FARIA, L.C. de; DEL PELOSO, M.J.; DÍAZ, J.L.C.; WENDLAND, A. Indicação de cultivares de feijoeiro-comum baseada na avaliação conjunta de diferentes épocas de semeadura. Pesquisa Agropecuária Brasileira, v.45, p.571-578, 2010 .

PIROLA, L.H.; RAMALHO, M.A.P.; CARNEIRO, J.E.S.;ABREU, $\hat{A}$. de F.B. Natural selection and family $x$ location interaction in the common (dry) bean plant. Genetics and Molecular Biology, v.25, p.343-347, 2002.

RAMALHO, M.A.P.; ABREU, Â. de F.B. Cultivares. In: VIEIRA, C.; PAUlA JÚNIOR, T.J. de; BORÉM, A. (Ed.). Feijão. 2.ed. Viçosa: UFV, 2006. p.415-436.

RAMALHO, M.A.P.; ABREU, Â. de F.B.; RIGHETTO, G.U. Interação de cultivares de feijão por épocas de semeadura em diferentes localidades do Estado de Minas Gerais. Pesquisa Agropecuária Brasileira, v.28, p.1183-1189, 1993.

RAMALHO, M.A.P.; ABREU, Â. de F.B.; SANTOS, P.S.J. Interações genótipos x épocas de semeadura, anos e locais na avaliação de cultivares de feijão nas regiões sul e Alto Paranaíba em Minas Gerais. Ciência e Agrotecnologia, v.22, p.176-181, 1998.

RESENDE, M.D.V. de; DUARTE, J.B. Precisão e controle de qualidade em experimentos de avaliação de cultivares. Pesquisa Agropecuária Tropical, v.37, p.182-194, 2007.

ROCHA, F. da; TOALDO, D.; BARILI, L.D.; VALE, N.M. do; GARCIA, S.; COIMBRA, J.L.M.; VOGT, G.A.; GUIDOLIN, A.F. Efeito de ambiente sobre a produtividade de feijão carioca para o Estado de Santa Catarina. Bragantia, v.68, p.621-627, 2009.

SAS INSTITUTE. SAS/STAT: user's guide. Version 9.2. Cary: SAS Institute, 2008. 584p.

SILVA, N.O.; RAMALHO, M.A.P.; ABREU, Â. de F.B.; CARNEIRO, J.E. de S. Performance of common bean families after different generations under natural selection. Genetics and Molecular Biology, v.27, p.574-578, 2004.

WRICKE, G. Zur Berechnung der Ökovalenz bei Sommerweizen und HafeR. Zeitschrift für Pflanzenzüchtung, v.52, p.127-138, 1964.

Recebido em 8 de novembro de 2010 e aprovado em 16 de julho de 2011 